\title{
Economic Design of Reinforced Concrete Conical Shells
}

\author{
Asst. Prof. Dr. Khattab Saleem Abdul-Razzaq \\ University of Diyala $\backslash$ College of Engineering $\backslash$ Department of Civil Engineering
}

\begin{abstract}
This work presents economic reinforced concrete conical shells dimensions and reinforcement in order to save time and efforts of the designers who aim to design conical shells economically from $5 \mathrm{~m}$ to $20 \mathrm{~m}$ spans. In addition to that, this work presents the economic shell raise $\left(h_{e c}\right)$ vs. span $(D)$ formula that gives lowest construction cost.

The considered loads are the own weight of the shell body, external finishing by glazed brick and internal finishing layer of gypsum plaster (juss). As well as the dead load, live load is considered too. A computer program is written in the Visual Basic programming language. This computer program consists of two parts. The first part is the linear analysis using the membrane theory formulas to get the forces at the crown and at the support of the shell.

The second part uses Nelder and Mead's minimization method to minimize the total cost formula (objective function). Three types of constrains confine this minimization regarding to strength, buckling and accuracy of the analysis method. The minimization variables are two; shell rise ( $h)$ and shell thickness $(t)$.

The two parts of the computer program are connected together in a force and cost convergence iterative loop in order to get the dimensions and reinforcement ratios that lead to the minimum cost.
\end{abstract}

Keywords: Economic, Design, Reinforced Concrete, Conical, Shells.

\section{Introduction}

Shells are back again in Iraq. They are early recognized with specific houses of those who consider them a symbol of Iraqi architecture ${ }^{[1]}$, beauty and luxury at the same time.

Nowadays, shells are widely constructed in Baghdad. Shells built with brick, reinforced concrete or steel; separated or overlapped are widely constructed. This is why this work is implemented to answer the question: What are the dimensions and reinforcement ratios that give the economical design of conical shells?

It is known that when the conical shell is shallow, i.e. the rise (h) is small, the support angle with the horizon (v) decreases, so the horizontal component $(\mathrm{Fx})$ of the thrust force $\left(\mathrm{N}_{\text {thrust }}\right)$ increases, see figure (1). This leads to an increment in the dimensions and reinforcement of the edge ring beam that raises the total cost of the conical shell.

In other hand, when the conical shell is high, i.e. (h) is big, the dome becomes bigger and the shell becomes thicker which also raise the total cost of the conical shell in spite of the nonexistence need to an expensive edge ring beam.

Therefore, there is a specific solution lies between the high shell and the low one, i.e. a balance among the dimensions of the shell in some way that leads to the minimum cost.

\section{Some of Previous Studies}

According to the amount and variation of shells constructed from 1920 to 1970, this period of time can be considered the golden time of the reinforced concrete shell construction. Later, reinforced concrete shells began to get less attention. Fewer technical research works are published on their design methods and construction techniques, and the amount of signature shells constructed declined noticeably. Ekkehard Ramm and Gerhard Mehlhorn (1991) discussed the analyses of reinforced concrete shells at ultimate loading. After a brief review of the material models used, the authors presented selected examples such as conical shaped cooling towers that experimentally discussed as a free form model shell through discussing various form-finding approaches for the shape of shells free form ${ }^{[2]}$. M.H. Imam (1998) presented a shape optimization study for $4 \mathrm{~m}$ span umbrella-shaped axisymmetric shell of variable thickness with the self-weight as the dominant load. Constraints on the principal stresses at the critical points are taken into consideration as design criterion and the assessment of the uniaxial strength (compressive one) requirement is used as failure criterion ${ }^{[3]}$. M Z $\mathbf{Z ~ K a b i r}$ and A Rojhani Shirazi (2008) studied the optimum minimum weight laminate configuration for lament-wound laminated conical shells under buckling load. Based on the characteristic buckling behavior takes place in laminated conical shells, the common penalty function technique is used to solve the optimization problem in addition to reduce the computational cost related to it ${ }^{[4]}$. Antonio Tomás and Pascual Martí (2010) presented an aesthetic appearance like initially planned by the designer. The results show that important improvements in the structural behaviour may be reached with only small geometric changes. They showed how increasing the 
geometric curvatures, taking a higher elastic modulus of the concrete into considerations and increasing the thickness of shell affect the optimum solution ${ }^{[5]}$. Milaji $\square$ Aleksandar et al (2013) tried to reduce the gap between practice and theory in the field of optimum design of the RC structures by highlighting the importance of evaluating the obtained solutions from the practical side. In addition to that, Authors provided a brief overview of existing solutions up to 2013 in order to enable researchers to find the adequate comparison criteria and benchmark problems for their solutions of the optimization problem ${ }^{[6]}$.

\section{Objective Function}

The objective function of the research, which should be minimized, is the cost function. Cost function includes the costs of concrete volume of the shell body, concrete volume of the edge ring beam and the reinforcement for both involving labor cost. This cost also includes the external and internal finishing of the shell body in addition to the labor cost:

$\mathrm{Z}=\mathrm{Z}_{\mathrm{s}}+\mathrm{Z}_{\mathrm{B}}+\mathrm{Z}_{\mathrm{th}}+\mathrm{Z}_{\mathrm{h}}+\mathrm{Z}_{\mathrm{mB}}+\mathrm{Z}_{\mathrm{sB}}$

Where:

$\mathrm{Z}=$ total cost of the shell

$Z_{\mathrm{s}} \quad=\quad$ cost of the concrete shell body

$Z_{\mathrm{B}}=$ cost of the concrete ring beam

$Z_{\text {th }}=$ cost of the thrust steel reinforcement for the shell body

$\mathrm{Z}_{\mathrm{h}} \quad=\quad$ cost of the hoop steel reinforcement for the shell body

$\mathrm{Z}_{\mathrm{mB}}=$ cost of the main steel reinforcement for the ring beam

$\mathrm{Z}_{\mathrm{sB}}=$ cost of the shear steel reinforcement for the ring beam

Equation (1) could be written in more detailed form:

$$
\begin{aligned}
= & \mathrm{Vol}_{\mathrm{sh}} * \mathrm{Cc}+\mathrm{Vol}_{\mathrm{B}} * \mathrm{Cc}+\mathrm{Vol}_{\mathrm{sth}} * \gamma_{\mathrm{s}} * \mathrm{Cs}+\mathrm{Vol}_{\mathrm{sho}} * \gamma_{\mathrm{s}} * \mathrm{Cs}+\mathrm{Vol}_{\mathrm{stB}} * \gamma_{\mathrm{s}} \\
& * \mathrm{Cs}+\mathrm{A}_{\text {int }} * \mathrm{C}_{\text {fint }}+\mathrm{A}_{\mathrm{ext}} * \mathrm{C}_{\mathrm{fext}}+4 \mathrm{a} * \mathrm{no} * \mathrm{C}_{\mathrm{st}}
\end{aligned}
$$

\begin{tabular}{|c|c|c|}
\hline $\mathrm{Vol}_{\text {sh }}$ & $=$ & concrete volume of the shell body \\
\hline $\mathrm{Vol}_{\mathrm{B}}$ & $=$ & concrete volume of the edge ring beam \\
\hline $\mathrm{Vol}_{\text {sth }}$ & $=$ & volume of meridional steel reinforcement of the shell \\
\hline $\mathrm{Vol}_{\text {sho }}$ & $=$ & volume of hoop steel reinforcement of the shell \\
\hline $\mathrm{Vol}_{\mathrm{stB}}$ & $=$ & volume of main reinforcement of the ring beam \\
\hline $\mathrm{A}_{\text {int }}$ & $=$ & internal surface area of the shell \\
\hline$A_{\text {ext }}$ & $=$ & external surface area of the shell \\
\hline $\mathrm{Cc}$ & $=$ & concrete unit price $\left(u n i t / \mathrm{m}^{3}\right)$ including labor cost \\
\hline Cs & $=$ & reinforcement steel unit price (unit/ton) including labor cost \\
\hline $\mathrm{C}_{\text {fint }}$ & $=$ & juss unit price $\left(u n i t / \mathrm{m}^{2}\right)$ including labor cost \\
\hline $\mathrm{C}_{\mathrm{fext}}$ & $=$ & glazed tiles unit price (unit $/ \mathrm{m}^{2}$ ) including labor cost \\
\hline $\mathrm{C}_{\mathrm{st}}$ & $=$ & stirrup unit price including labor cost (unit/stirrup) \\
\hline$\gamma_{\mathrm{s}}$ & $=$ & reinforcement steel density $\left(\right.$ ton $\left./ \mathrm{m}^{3}\right)$ \\
\hline $\mathrm{d}$ & $=$ & dimension of the square ring beam \\
\hline 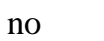 & $=$ & number of ring beam stirrups reinforcement \\
\hline
\end{tabular}

Where:

It is worth to mention that $\mathrm{Vol}_{\text {sh }}, \mathrm{Vol}_{\mathrm{B}}, \mathrm{A}_{\mathrm{int}}$ and $\mathrm{A}_{\mathrm{ext}}$ are calculated as follow:

$\mathrm{Vol}_{\mathrm{sh}}=\pi \cdot 0.5 \mathrm{D} . \mathrm{S} . \mathrm{t}$

$\mathrm{Vol}_{\mathrm{B}}=\mathrm{a}^{2} \cdot \pi \cdot \mathrm{D}$

$\mathrm{A}_{\mathrm{int}} \approx \mathrm{A}_{\mathrm{ext}}=0.5 \mathrm{D} \cdot \mathrm{S} \cdot \pi$

Where:

$\begin{array}{lll}\mathrm{D} & = & \text { shell span } \\ \mathrm{S} & = & \text { shell slant } \\ \mathrm{t} & = & \text { shell thickness }\end{array}$

IV. Minimization Technique

Nelder and Mead's method ${ }^{[7]}$ is used to minimize the objective function mentioned earlier. The idea of this method is to compare the values of the cost function at (number of variables +1 ) vertices of the simplex and 
move the simplex towards the minimum point during the iterative process. This search for the minimum $\mathrm{Z}$ value is conditioned by specific limitations.

\section{Design Variables}

The minimization process, which is applied on the objective function, is through varying the values of the design variables in a way that gives the minimum value of $(\mathrm{Z})$. Rise $(\mathrm{h})$ and thickness $(\mathrm{t})$ of the shell are independent design variables, while the other design variables such as reinforcement ratios for shell $\left(\rho_{\text {slab }}\right)$ and beam $\left(\rho_{\text {beam }}\right)$, beam stirrups (strps) and ring beam dimension (a) depend on the values of (h) and $(t)$ obtained from minimization process.

\section{Minimization Constraints}

In order to get the minimum cost for the conical shell, $\mathrm{Z}$ function should be minimized, but minimization is limited by the requirements of strength requirements, buckling considerations and adequacy of membrane theory use:

\section{VI.I Strength requirements:}

a) Hoop stress in concrete $\left(\sigma_{\mathrm{H}}\right)$ should not exceed the allowable limit:

$\sigma_{\mathrm{H}}\left[f_{\mathrm{t}}\right.$

$\frac{N_{\text {hoop }}}{t} \leq f_{t}$

Where

$f_{\mathrm{t}} \quad=\quad$ Allowable tensile strength for concrete

$\mathrm{t} \quad=\quad$ Shell thickness

$\mathrm{N}_{\text {hoop }} \quad=\quad$ Hoop unit forces

b) Thrust stress in concrete $\left(\sigma_{\mathrm{TH}}\right)$ should not exceed the allowable compressive strength for the concrete:

$\sigma_{\mathrm{TH}}\left[f_{\mathrm{c}}^{\prime}\right.$

$\frac{N_{\text {thrust }}}{t} \leq f_{c}^{\prime}$

Where

$f_{c}^{\prime} \quad=\quad$ Allowable compressive strength for concrete

$\mathrm{N}_{\text {thrust }} \quad=\quad$ Meridional unit forces

\section{VI.II Buckling Considerations:}

Calculations for stability in thin conical shells in a nonlinear formulation can be found in the literature ${ }^{[8]}$. The author derived and simplified the differential equation for conical shells, and on that basis, derived theoretical formulas for determining buckling load and buckling stress in axial compression:

$\sigma_{\mathrm{T}}\left[\sigma_{\mathrm{cr}}\right.$

$\frac{N_{\text {thrust }}}{t} \leq \sigma_{c r}$

Buckling allowable stress $\left(\sigma_{\mathrm{cr}}\right)$ can be defined by the following formula ${ }^{[8]}$ :

$\sigma_{c r}=\frac{0.195 E . t}{r}$

Where:

$\mathrm{E} \quad=\quad$ elastic modulus

$\mathrm{r}=\quad$ principal radius of curvature at the point studied for stability

\section{VI.III Membrane Theory Adequacy:}

In order to ensure the accuracy of the elastic analysis made by the membrane theory, it should be guaranteed that the ratio of shell thickness ( $t$ ) to the shell radius of curvature ( $r$ ) should be within the range identified below ${ }^{[9 \& 10]}$ : 
$\frac{1}{200} \leq \frac{t}{r} \leq \frac{1}{25}$

\section{Design Example}

In order to clarify the membrane theory analysis and design details, a design example of a conical roof covers a hall having a diameter of $20 \mathrm{~m}$ is presented here. The rise of the conical dome has to be $4 \mathrm{~m}$. Live load $(\mathrm{LL})$ is considered $1500 \mathrm{~N} / \mathrm{m}^{2}$, see figure (1).
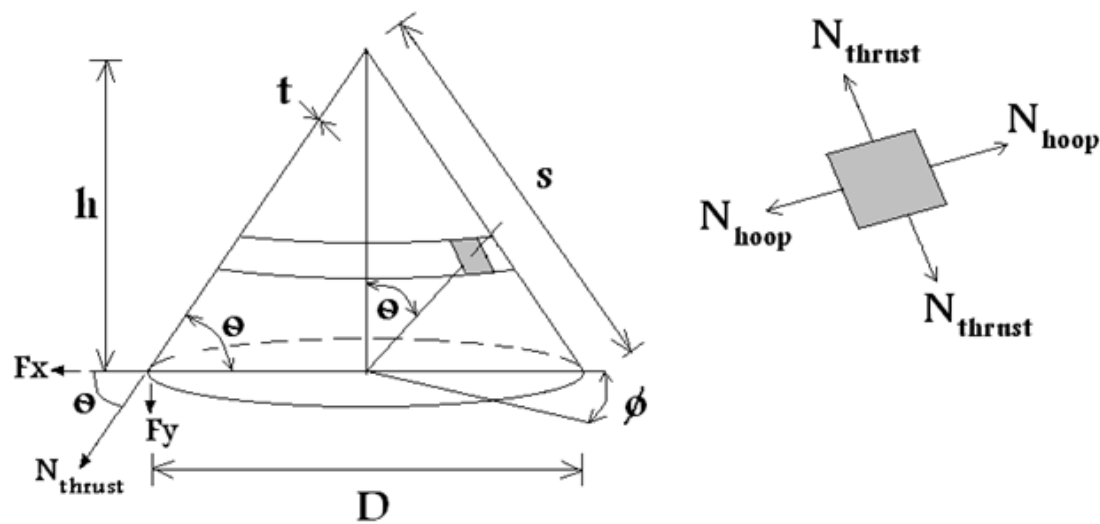

Figure (1)

1- Geometry of the shell:

Diameter $\mathrm{D}=20 \mathrm{~m}$

$$
\begin{aligned}
& \text { rise } \quad h=4 \mathrm{~m} \\
& \tan v=10 / 4=2.5 ; \text { then } v=68^{\circ} 12^{\prime} \\
& \sin v=0.9285 ; \cos v=0.3714
\end{aligned}
$$

\section{2- Loading:}

Let the thickness of the shell be $15 \mathrm{~cm}$

Weight of dome shell $/ \mathrm{m}^{2}=0.15 * 1 * 23000+(0.02+0.04) * 1 * 20000=4650 \mathrm{~N}$

$\mathrm{W}_{\mathrm{u}}=1.2(4650)+1.6(1500)=7980 \mathrm{~N} / \mathrm{m}^{2}$

\section{3- Calculation of stresses:}

Thrust $\quad N_{\text {thrust }}=\frac{W_{u} \cdot h}{2 \cos ^{2} \theta}$

Maximum $\mathrm{N}_{\text {thrust }}$ will occur at the base where $\mathrm{h}=4 \mathrm{~m}$

$N_{\text {thrust }_{\max }}=\frac{7980(4)}{2(0.3714)^{2}}=115704.2 \mathrm{~N}$ (comp.)

Thrust stresses :

$$
\frac{115704.2}{150(1000)}=0.771 \mathrm{~N} / \mathrm{mm}^{2} \quad(\text { Safe })
$$

Hoop force:

$\mathrm{N}_{\text {hoop }}=\mathrm{W}_{\mathrm{u}} \cdot \mathrm{h} \cdot \tan ^{2} \mathrm{v}$

$\mathrm{N}_{\text {hoop)max }}=7980$ (4) $(2.5)^{2}=199500 \mathrm{~N}$ (comp.)

Hoop stresses :

$$
\frac{199500}{150(1000)}=1.33 \mathrm{~N} / \mathrm{mm}^{2}(\text { Safe })
$$

\section{4- Steel reinforcement based on ACI 318-11 ${ }^{[11]}$ :}

The stresses work out to be safe. Hence only nominal reinforcement has to be provided $0.18 \%$ of the area of concrete.

$A s_{\text {min }}=0.0018(150) 1000=270 \mathrm{~mm}^{2}$

Using $12 \mathrm{~mm} \phi$ bars, $\mathrm{A}_{\mathrm{b}}=113 \mathrm{~mm}^{2}$ 
Spacing $=\frac{1000\left(A_{b}\right)}{A s_{\min }}=\frac{1000(113)}{270}=418 \mathrm{~mm}$

Maximum Spacing is $2 \mathrm{t}=2(150 \mathrm{~mm})=300 \mathrm{~mm}$

Use 12mm $\phi$ bars @ $300 \mathrm{~mm}$ c/c both directions

The meridional bars may be disconnected near apex, and a wire mesh may be provided there to avoid congestion of steel.

\section{5- Design of ring beam:}

Horizontal component $(\mathrm{Fx})$ of meridional thrust $\mathrm{N}_{\text {thrust }}$ will cause an outward force on the support, causing hoop tension. Hence, a ring beam is necessary.

Hoop tension $\mathrm{P}$ in ring beam:

$\mathrm{N}_{\text {thrust }} \operatorname{sinu}=115704.2(0.9285)=107431.35 \mathrm{~N} / \mathrm{m}$

Total tensile force:

$\mathrm{P}(0.5 \mathrm{D})=107431.35(0.5) 20=1074313.5 \mathrm{~N}$

Area of steel to resist this:

As $=\frac{1074313.5}{140}=7673.3 \mathrm{~mm}^{2}$

Using $25 \mathrm{~mm} \phi$ bars, $A_{b}=490 \mathrm{~mm}^{2}$

No. of bars $=\frac{7673.7}{490} \approx 16$ bars

Actual area of steel provided $=7840 \mathrm{~mm}^{2}$

Tie these by $12 \mathrm{~mm} \phi 2$-lgs stirrups @ 300mm c/c

Let $\left(\mathrm{a}^{2}\right)$ be the area of ring beam, equivalent area of composite section $=$

$\left(\mathrm{a}^{2}\right)+(\mathrm{m}-1)$ As $=\left(\mathrm{a}^{2}\right)+18(7840)=\left(\mathrm{a}^{2}\right)+141120$

Assuming the allowable tensile stress in composite section to be $1.2 \mathrm{~N} / \mathrm{mm}^{2}$, we have:

$\frac{1074313.5}{\left(\mathrm{a}^{2}\right)+141120}=1.2$

Which gives $\mathrm{a}^{2}=754141.25 \mathrm{~mm}^{2}$

Provide ring beam of size $875 \mathrm{~mm} \times 875 \mathrm{~mm}$

$\rho=\frac{7840}{(875)(800)}=0.0112$

$\rho_{\max }=0.85(0.85) \frac{25}{400} \frac{0.003}{0.003+0.004}=0.01935>\rho \quad o . k$.

The details of the reinforcement are shown in figure (2).

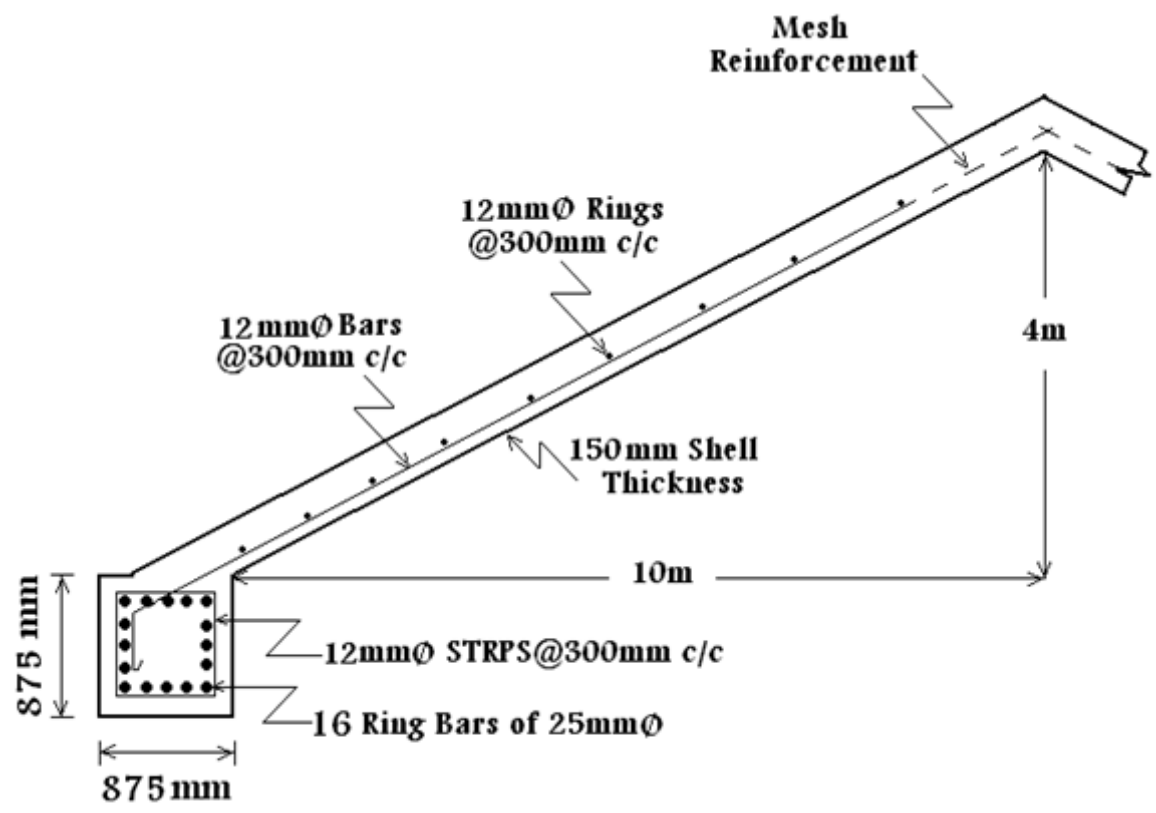

Figure (2): Design details 


\section{Computer Program}

This computer program, see figure (3), is written in the Visual Basic programming language. This computer program consists of two parts. The first part is the linear analysis using the membrane theory formulas to get the forces at the crown and at the support of the shell.

Running this program starts with feeding the values of shell span (D), dome rise (h), concrete compressive strength $\left(f_{c}^{\prime}\right)$, allowable tensile strength for concrete $\left(f_{t}\right)$, yield of steel stress (fy), density of concrete $\left(\gamma_{c}\right)$, density of steel $\left(\gamma_{s}\right)$ and shell thickness $(t)$.

According to the values of span (D), shell thickness (t), and shell rise (h), the linear analysis takes place by the program on the base of the membrane theory closed form solution. The program calculates the forces $\left(\mathrm{N}_{\text {hoop }}\right)$ and $\left(\mathrm{N}_{\text {thrust }}\right)$ at the support and at the crown of the conical shell. After that, the program calculates the hoop stresses $\left(\sigma_{\mathrm{H}}\right)$ and thrust $\left(\sigma_{\mathrm{TH}}\right)$ by dividing the calculated forces by the thickness $(\mathrm{t})$. Then, the program checks the stresses with the allowance of crushing and buckling.

At the following step, the program calculates the required reinforcement steel areas in both directions $\left(A s_{\text {hoop }}\right)$ and $\left(\mathrm{As}_{\text {thrust }}\right)$ at the support and the crown of the shell. After that, the program indicates the dimensions and the required steel reinforcement for the ring beam.

The second part of the program uses Nelder and Mead's minimization method to minimize the total cost formula (objective function). Three types of constrains confine this minimization. The minimization variables are two; rise $(\mathrm{h})$ and thickness $(\mathrm{t})$.

Force and cost convergence iterative loops are connecting the two program parts to reach the minimum cost.

The output of the program is shell span (D), economic rise $\left(\mathrm{h}_{\mathrm{ec}}\right)$, shell slab thickness $(\mathrm{t})$, slab reinforcement details, ring beam dimension (a), ring beam reinforcement and total cost $(\mathrm{Z})$.

\section{Results and Conclusions}

Using the written design computer program, the economic design dimensions and reinforcement for $5 \mathrm{~m}$ $-20 \mathrm{~m}$ conical shells are given in the following table:

Economic Design Dimensions, Reinforcement and Cost

\begin{tabular}{|l|l|l|l|l|l|l|l|l|l|}
\hline $\begin{array}{l}\text { Span } \\
(\mathrm{m}) \\
\mathrm{D}\end{array}$ & $\begin{array}{l}\text { Rise } \\
(\mathrm{m}) \\
\mathrm{h}\end{array}$ & $\begin{array}{l}\text { Thick- } \\
\text { ness } \\
(\mathrm{mm})\end{array}$ & $\begin{array}{l}\text { Reinforce- } \\
\text { ment } \\
\text { for slab } \\
\text { (both ways) }\end{array}$ & $\begin{array}{l}\text { Reinf. } \\
\text { ratio } \\
\rho_{\text {slab }}\end{array}$ & $\begin{array}{l}\text { Beam } \\
\text { Dimen- } \\
\text { sions } \\
(\mathrm{m})\end{array}$ & $\begin{array}{l}\text { Reinforce- } \\
\text { ment } \\
\text { for beam }\end{array}$ & $\begin{array}{l}\text { Reinf. } \\
\text { ratio } \\
\rho_{\text {beam }}\end{array}$ & $\begin{array}{l}\text { Stir- } \\
\text { rups } \\
\text { for Beam }\end{array}$ & $\begin{array}{l}\text { Total } \\
\text { Cost } \\
\text { (unit) }\end{array}$ \\
\hline 5 & 0.625 & 75 & $\begin{array}{l}\emptyset 8 @ \\
350 \mathrm{~mm}\end{array}$ & 0.0018 & $0.2 * 0.2$ & $4-\varnothing 12$ & 0.01130 & $\begin{array}{l}\emptyset 6 @ \\
300 \mathrm{~mm}\end{array}$ & 634 \\
\hline 10 & 2.5 & 100 & $\begin{array}{l}\emptyset 10 \mathrm{~mm} \\
@ 425 \mathrm{~mm}\end{array}$ & 0.0018 & $0.3 * 0.3$ & $8-\varnothing 12 \mathrm{~mm}$ & 0.010053 & $\begin{array}{l}\emptyset 8 \mathrm{~mm} @ \\
300 \mathrm{~mm}\end{array}$ & 3476 \\
\hline 15 & 4.1 & 125 & $\varnothing 12 @ 450 \mathrm{~mm}$ & 0.0018 & $0.5 * 0.5$ & $12-\varnothing 16$ & 0.00965 & $\begin{array}{l}\emptyset 10 @ 300 \\
\mathrm{~mm}\end{array}$ & 12609 \\
\hline 20 & 6.9 & 150 & $\varnothing 16 @ 450 \mathrm{~mm}$ & 0.0018 & $0.6 * 0.6$ & $8-\varnothing 25$ & 0.01090 & $\begin{array}{l}\emptyset 12 @ 300 \\
\mathrm{~mm}\end{array}$ & 30700 \\
\hline
\end{tabular}

Economical dimensions can be summarized by figure (3):

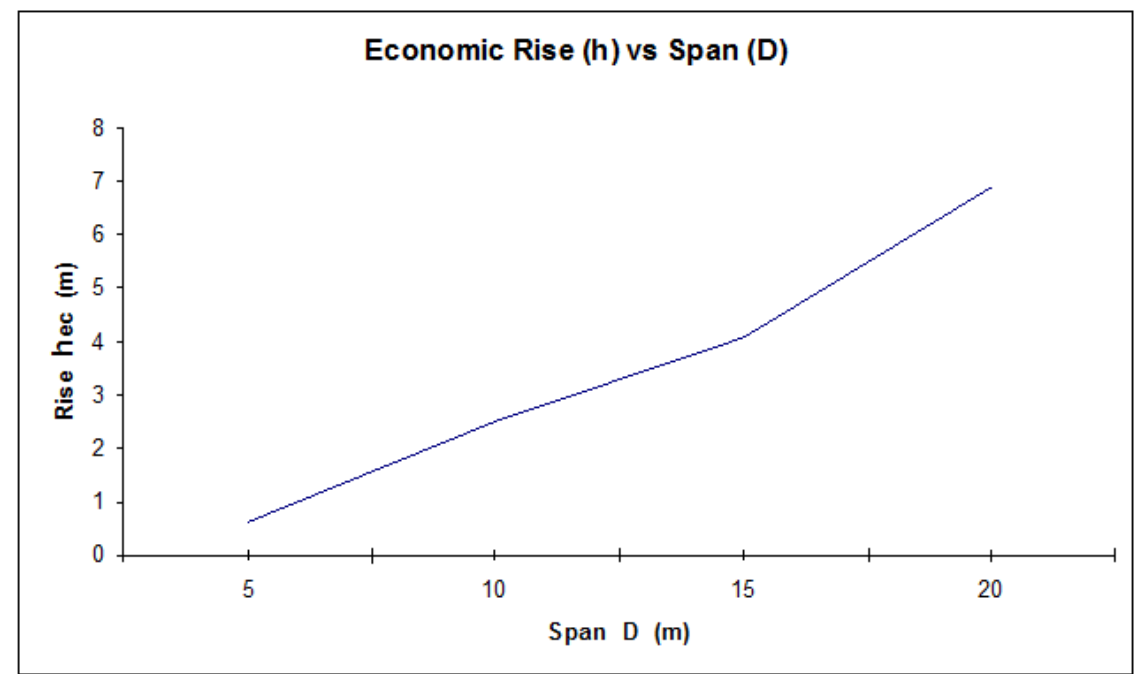

Figure (3): Economic Rise $\left(\mathrm{h}_{\mathrm{ec}}\right)$ vs Span of the Conical Shells (D) relationship for spans vary from $5 \mathrm{~m}$ to $20 \mathrm{~m}$ 
The curve of the economic rise $\left(h_{\mathrm{ec}}\right)$ vs span of the conical shells from $5 \mathrm{~m}$ to $20 \mathrm{~m}$ spans can be expressed by the following formula:

$$
h_{e c}=\frac{D^{3}}{508.4746}-0.0645 D^{2}+0.99833 D-3
$$

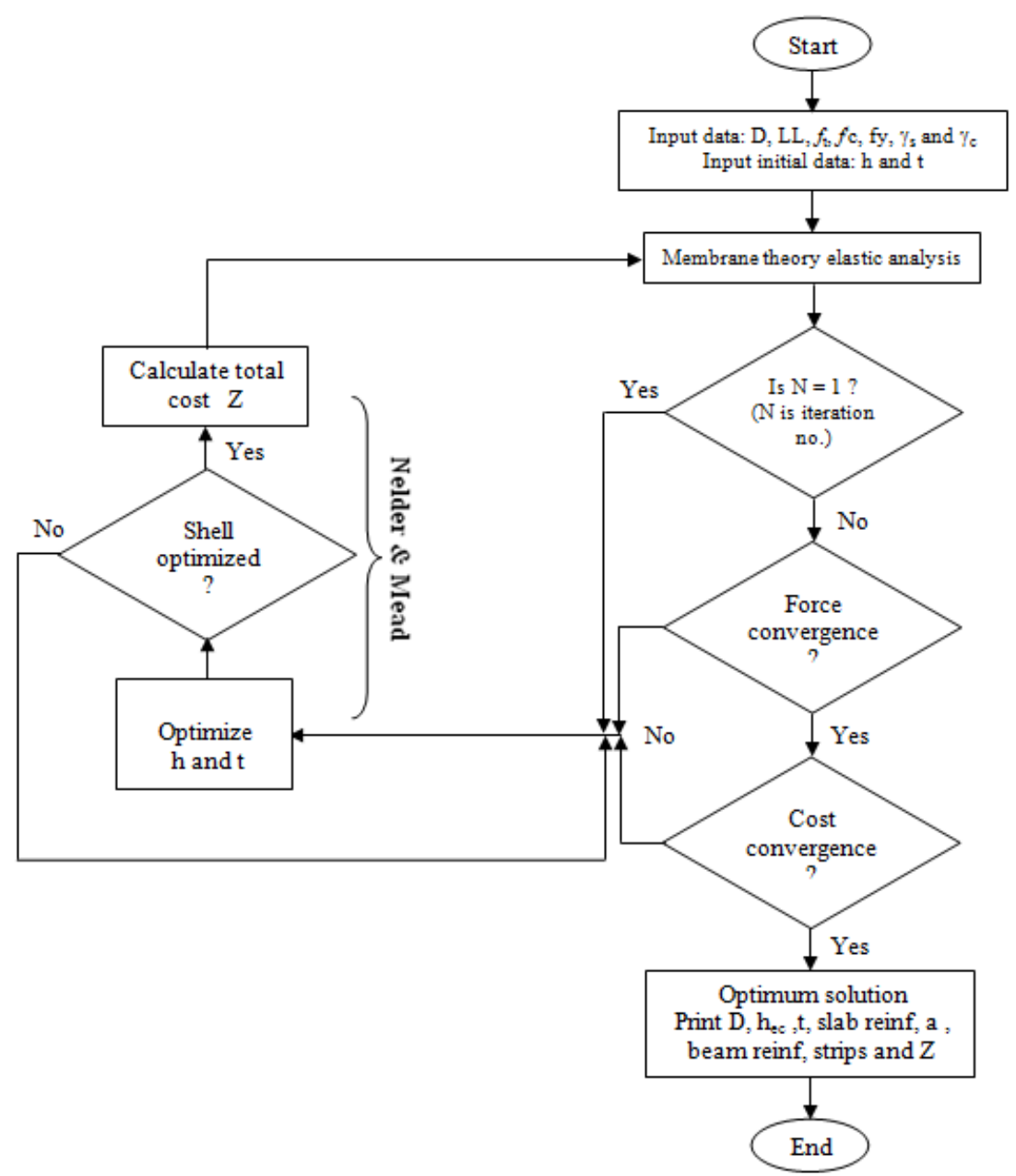

Figure (3): Program Structure

\section{References}

[1]. Atta al Hadithi and Hana A. Khaliq, "Conical Domes in Iraq", Ministry of Information, Directorate General of Antiquities, Republic of Iraq, Baghdad 1974.

[2]. Ekkehard Ramm and Gerhard Mehlhorn, "On shape finding methods and ultimate load analyses of reinforced concrete shells", Engineering Structures, Volume 13, Issue 2, April 1991, pp. 178-198.

[3]. M.H. Imam, "Shape optimization of umbrella-shaped concrete shells subjected to self-weight as the dominant load", Computers \& Structures, Volume 69, Issue 4, November 1998, pp. 513-524.

[4]. M Z Kabir and A Rojhani Shirazi, "Optimum Design of FilamentWound Laminated Conical Shells for Buckling Using the Penalty Function", JAST, Vol No 5. pp 115-121, Iranian Aerospace Society September 2008.

[5]. Antonio Tomás and Pascual Martí, "Shape and size optimisation of concrete shells", Elsevier, Engineering Structures, 32 (2010), pp. 1650-1658.

[6]. Milajić Aleksandar, Pejičić Goran and Beljaković Dejan, "Optimal structural design of reinforced concrete structures - review of existing solutions considering applicability aspect", Archives for Technical Sciences 2013, 9(1), pp. 53-60.

[7]. Brain D. Bunday, B. Sc., Ph.D., F.S.S., F.I.M.A., "Basic Optimization Methods", Edward Arnold (Australia) Pty Ltd, 1985.

[8]. A. V. Sachenkov, "Approximate Determination of the lower Buckling Stress limit in Longitudinal Compression of a Thin - Walled Conical Shell”, Izvestiya Kazan, Filiala Akad, Nauk SSSR, No. 7, 1955.

[9]. Gibson J. E., "Thin Shells, Computing and Theory", The City University, London 1908.

[10]. Gioncu V., "Thin Reinforced Concrete Shells, John Wiley and Sons, Ltd., Printed in Romania, 1979.

[11]. Building Code Requirements for Structural Concrete 2011, (ACI 318M-11) and Commentary. 